\title{
Learning to Think-with: Feminist Epistemology and the Practice-based Medical Humanities
}

\author{
Jo Winning ${ }^{1 *}$
}

Published: September 27, 2018

\begin{abstract}
This paper begins at the place of practice, immersed in the messy real-life clinical setting, with the tensions, errors and affects that suffuse healthcare and its delivery, using the recent case of Hadiza Bawa-Garba's conviction for manslaughter and lifetime ban from the medical profession, after the death of Jack Adcock, a 6-year-old boy in her care, in 2011. From a feminist perspective, the vocabulary missing from this 'watershed' case in the UK is that the gendered, classed and raced subjectivities of the clinician, patient and family are caught up in this tragic set of events. Such examples from clinical practice may seem a long way from the conceptual fields of medical humanities. This paper argues that they are not. It proposes that we require a new methodology of the practice-based medical humanities which deploys socio-political, cultural and conceptual frameworks to expand the capacities of clinical training and practice. Practice-based medical humanities require an underpinning by feminist epistemology. Using Haraway's 'sym-poesis' and Despret's 'thinking-with' as models of thinking offers radical potential for reconceptualising the lived experiences of clinical practice and patient care. Such principles allow the full complexities of identity to emerge within the clinical setting.
\end{abstract}

Keywords: clinical practice, feminist epistemology, practice-based medical humanities

\section{INTRODUCTION}

This paper locates itself at the place of practice, immersed in the messy real-life clinical setting, with the tensions, errors and anxieties that suffuse healthcare and its delivery, and might perhaps be epitomised, in their most intense iteration, by the recent case of Dr Hadiza Bawa-Garba's conviction for manslaughter and lifetime ban from the medical profession, after the death of Jack Adcock, a six-year-old boy in her care, in 2011. Such an example from clinical practice may seem a very long way indeed from the conceptual fields of medical humanities. This paper argues it is not. It proposes that alongside the new iterations of the field of medical humanities that are emerging, we urgently require a new methodology of the practice-based medical humanities. A practice-based approach means keeping a grounded focus on clinical training and practice whilst deploying the socio-political and cultural vocabularies and conceptual frameworks of the humanities disciplines to understand them. Furthermore, this paper will argue that some of the most productive conceptual frameworks available to medical humanities come from those bodies of critical thought that have already tussled with the complex relationship between theory and practice, between the conceptual understanding of lived experience and the actions required for tangible change. In this regard, I will argue that feminist epistemology, with its modes of thinking that of necessity have involved acknowledgement of materiality and embodiment, and which have a long history of negotiating lived experience alongside social and political change, provides the most radical and productive underpinning for the practice-based medical humanities.

\section{A NEW EPISTEME}

It has been a commonplace to describe medical humanities as an emerging field for some time, despite the fact that the field has been under construction in multiple guises since the first use of the term in 1947 by the Belgian chemist and historian of science George Sarton (Bates et al., 2013). Medical humanities is a highly contested field and the parameters of exactly how it should be constituted, and to what ends its insights might be put, is currently 
a heavily-debated point of discussion. In their introduction to The Edinburgh Companion to the Critical Medical Humanities, Angela Woods and Anne Whitehead describe what they term 'the first-wave or mainstream' medical humanities as a field obsessed with 'the primal scene' of the clinical encounter between doctor and patient, a field built upon the naïve liberal humanist conviction that a simple engagement with the arts and the refraction of clinical practice through humanities' lenses will 'humanise' medicine and enrich the clinical encounter with reinvigorated empathy on the part of the clinician (Whitehead and Woods, 2016: 2). By contrast, they refer to the critical medical humanities as the second-wave and outline a field which interrogates the primal scene but also moves 'to explore new scenes and sites that may be equally important to our understandings of health and illness', as well as an orientation towards critique and theorisation of health, illness, well-being, medicine and healthcare (Whitehead and Woods, 2016: 2). Drawing on the work of Felicity Callard and Des Fitzgerald, Woods and Whitehead pay particular attention to the new ' $\mathrm{E}$ ' - the concept of entanglement - which the critical medical humanities contributes to the four existing 'E's of ethics, education, experience and empathy, which have dominated the first-wave (Fitzgerald and Callard, 2016: 5). Entanglement, which draws on the work of the feminist theorist Karen Barad, identifies both the material circumstances of knowledge-production but also the intrinsic enmeshment of humanities and biomedicine as modes of human knowing (Barad, 2007). As Fitzgerald and Callard argue, its potential is not simply as a 'new metaphor' but rather 'to break open the two halves' of the term 'medical humanities' to demonstrate:

that the complex of human life and medical science becomes [...] a series of 'repeated crossings, an ongoing conversation - a repetitive material semiotics, or a working out of a new reality'. (Fitzgerald and Callard, 2016: 41-42) ${ }^{1}$

What is at stake here in the 'second wave' reconceptualisation of the field and its critical methodologies, is the refusal to have the humanities disciplines instrumentalised in the service of biomedicine, as 'pleasant (but more or less inconsequential) helpmeets' who contribute suggestions about some of the tricky dilemmas that emerge in clinical practice and medical education (Fitzgerald and Callard, 2016: 35).

The tensions inherent in the construction of medical humanities as either a paradigmatic framework or simply utilitarian application have recently been articulated by one of its founders, Robert S. Downie. In the 1990s, Downie, along with Sir Kenneth Calman, then Chief Medical Officer, mapped out the contribution that medical humanities could make, if included in the undergraduate medical curriculum and the key documents of governance, such as the General Medical Council's Tomorrow's Doctors (1993). By 2016, Downie decries the pull towards the academy and away from practice:

The dominant aim of the medical humanities seems now to be research rather than teaching. I commented [that] the introduction of the term 'medical humanities' has been unfortunate. The reason is that it has suggested that the 'medical humanities' comprise an academic subject. Now if something is to be an academic subject there must be research, and funding bodies such as Wellcome have given millions of pounds for research into this alleged subject. But the more 'academic' the practitioners of the medical humanities become the more they will drift away from their original educational purpose. The danger is that researchers in the medical bumanities will finish up speaking only to similar researchers rather than to the medical students and clinicians we originally hoped to interest. [emphasis mine] (Downie, 2016: 35)

Downie and Calman's vision for the field was one in which educational purpose was its primary aim, complementing biomedical scientific education by introducing students and trainees to philosophical, literary and aesthetic arguments and materials in order to develop their skills of communication and empathy. Whatever the limits to this version of what medical humanities should be designed to do, Downie's delineation of the potential for academic insularity, in which medical humanities becomes an academic field driven purely by research funding and unable to speak outside its own locale or communicate across communities of practice, is useful for the way it problematises the sequestration of knowledge production within what Pierre Bourdieu would define as the habitus of academic institutions (Bourdieu, 1984).

In this paper, I want to examine the risk of sequestration that medical humanities runs, and the concomitant potential failure to establish what Alan Bleakley describes as 'a constructively critical intervention that sets a climate for medicine's reformulation of its aims', thereby fulfilling the crucial role of 'interlocutor' that is 'vital to the development of medical practice and knowledge' (Bleakley, 2015: 49-50). I would argue that part of the problematic circularity of debates about whether medical humanities should, or should not, be participating in the construction of medical culture in its broadest sense (meaning biomedical research, medical training and clinical practice) is to see the domains of theory (humanities) and practice (medicine) as inherently separate. Indeed, I would contend this is a category error that places the humanities as critical practice outside the sphere of clinical practice, and not

${ }^{1}$ Fitzgerald and Callard quote Steve Hinchliffe. (2015). More than One World, More than One Health: Re-configuring Interspecies Health. Social Science and Medicine, 129, 28-35. 
as an intrinsic set of ideas, approaches and methodologies that are actually located within a compendium of resources essential to what medicine actually is and does. A parallel might be found in what Bruno Latour terms 'the new domain of scientific humanities'. He looks specifically at the work being undertaken in critical animal studies and argues that 'to understand what animals have to say, all the resources of science and of the humanities have to be put to work (Latour, 2016: vii).

In their recent intervention in the debates about what medical humanities is and can do, Julia Kristeva and Eivind Engebretsen argue that 'tackling entanglement requires more than the mere application of perspectives from the humanities on medicine and healthcare' (Kristeva et al., 2017: 56). They call for a 'fundamental rethinking of the medical humanities', a paradigm shift that reconfigures the relationship between the 'hard science' of biomedicine and the 'soft science' of cultural and critical analysis in the humanities (Kristeva et al., 2017: 55). Indeed, they repudiate this binary and call for its deconstruction. This is a radical and timely clarion call. As evidence for what a reconstructed map of the resources at hand to deal with illness would look like, in which medicine and humanities sit alongside each other as tools for care and cure, they offer the case study of Souad, 'a young teenage girl from a Muslim family' who is suffering from refractory anorexia (Kristeva et al., 2017: 57). Souad, who is 'at first reticent about psychotherapy', finally responds to a multicultural psychotherapeutic team who encourage her to '[narrate] her life and [express] her destructive urges and sufferings' (Kristeva et al., 2017: 57). The multicultural make-up of the team is a key factor, offering Souad a level of diverse, situated cultural understanding that slowly allows her to 'reconnect with the French language', and in particular read 'Arabic poetry translated into French' (Kristeva et al., 2017: 57). This engagement with language, Kristeva argues, '[fills] the "symbolic void" within Souad, and allows her to focus on 'new cultural, symbolic and linguistic attachments' in a way that allows her to 're-establish ties to the world and her own body' (Kristeva et al., 2017: 57). This successful treatment provides them with a model for the productive imbrication of the cultural and the clinical. In this example lie the ways of knowing derived from the humanities that inform practice. Of particular importance in this case history, and its subsequent analysis, is the way identity and cultural difference - both in terms of gender and ethnicity - can be thought, felt and addressed in the clinical practice. It is the conceptual framing provided by both feminist and postcolonial theory, as well as the modern social movements of feminism and the civil rights campaigns, that facilitate insightful practice. This emblematic case demonstrates very clearly the urgent need to broaden the horizons of medical practice by incorporating the psychosocial and cultural knowledge of identity formation and experience derived from feminist theory.

\section{FROM 'THINKING' TO 'THINKING-WITH'}

As Neville Chiavaroli has convincingly argued, 'an epistemological perspective enables the argument that the medical humanities are valuable not because they are more "humane", but because they help constitute what it means to think like a doctor' (Chiavaroli, 2017: 13). If we are to understand the humanities disciplines as an integral component of the epistemological framework necessary for the practice of medicine, the question that immediately presents itself is what kind of epistemology? Which models of thinking are we talking about? I argue that some of the most generative examples of thinking that facilitate deep analysis in the context of medicine come from recent feminist revisions of thinking as a research practice. As Virginia Woolf writes in Three Guineas, women

have always done their thinking from hand to mouth; not under the green lamps at study tables in the cloisters of secluded colleges. They have thought while they stirred the pot, while they rocked the cradle' (Woolf, (1993 [1938]): 187).

Woolf inspires new modes of thinking in the work of feminist theorists of science, Vinciane Despret and Isabelle Stengers. Whilst, they acknowledge, Woolf's address is situated at an historical remove of 70 years and a social remove in which women had only just started to enter professions and university education traditionally the preserve of men, it still carries substantial resonance today. Given the material circumstances of gendered experience that still prevail, it is prescient, they argue, to pose the question, 'what do women do to thought?' (Stengers and Despret, 2014: 77). It is the materiality of an existence shaped by doing and making, the work of the body, which modulates the way that intellectual work is undertaken. This is not to inscribe an essentialist paradigm they insist, but rather to deploy 'a perspective of gender' that is 'inseparable from practical, political, ethical, and aesthetic dimensions' (Stengers and Despret, 2014: 78). In other words, this is an account of thinking built from a perspective traditionally associated with women, which is to say the world of embodied, corporeal labour. 
Thinking, for Stengers and Despret, cannot be separated from practice; indeed practice is thinking and these two activities are so imbricated that it is a mistake to describe them as a binary:

When a scientist, male or female, although we could equally say a photographer or a talented cook, thinks, when he or she doubts or hopes, what makes them think, hesitate or hope is what makes them a scientist, photographer or talented cook' (Stengers and Despret, 2014: 80-81).

Invoking Woolf's constituency of address in Three Guineas, 'the daughters of educated men', Stengers and Despret note that "how to think" is not an abstract or reflexive question but is inseparable from what in their case is creative work, practice, and engagement' (Stengers and Despret, 2014: 82). Whilst this challenge to the division between thinking and practice is of considerable relevance to discussion of the field of medical humanities, Stengers and Despret's next conceptual move offers hugely productive insights into an epistemological framework for the practice-based medical humanities. If thinking is practice, then what does this mean for research methods when analysing human work and actions, especially when these belong to a domain outside the researcher's own experience? To put this more specifically, how should practice-based medical humanities situate itself in relation to clinical practice?

Stengers and Despret advance the concept of 'thinking-with' via the example of a research project that Despret undertakes with a colleague, Jocelyne Poucher. Despret, who works within the field of animal studies, seeks 'to explore the problem of the difference between animals and men' (Stengers and Despret, 2014: 84). She and Poucher believe they will amass useful evidence for this philosophical investigation if they speak to animal breeders about the practice of breeding within animal husbandry. They have a hypothesis that 'in breeding situations,' it is the animals as well as the breeders who do the work. Yet when Poucher puts this hypothesis to the breeders, she is met with 'blank looks: no, it's the people who work, the animals don't work' (Stengers and Despret, 2014: 85). What they learn is how to construct the question with the breeders:

We are not sure that our problem is of interest to breeders, or that the questions we are able to formulate are pertinent to them. Thus, according to you, as a breeder, how should we construct our question so that it has a chance at interesting those to whom we ask it and a chance of receiving interesting answers?' (Stengers and Despret, 2014: 85)

This 'thinking-with', which turns the research into an interlocution, yields striking results that '[assemble] everyone's intelligence: breeders, cows, pigs, investigators' (Stengers and Despret, 2014: 86). Moreover, it allows for difference and diversity to emerge within the research field, since the question is 'reprised and reinvented in other terms by each breeder' (Stengers and Despret, 2014: 86). To return to medicine, what happens if we substitute 'doctor' or 'patient' (or, for that matter, 'manager' or 'nurse') for 'breeder' in this statement? What emerges with spectacular clarity is the way it, for one thing, proposes a profound collectivity between practitioner and researcher and, for another, recalibrates the critical analysis of medical humanities so that it is not an external act of looking at medicine but rather a situated, collaborative endeavour of thinking-with. As Donna Haraway notes of Vinciane Despret's feminist philosophical work within the field of animal studies, 'her kind of thinking enlarges the capacity of all the players; that is her worlding practice'; worlding, for Haraway, refers to the systemic processes which create and shape experience in the world (Haraway, 2016: 7). This is the ambition, and indeed the ethical imperative, built on feminist epistemological practice, that I would hope for the practice-based medical humanities. What I offer in the following analysis of the Bawa-Garba case is an example of thinking-with that aims to contribute to our (by which I mean the whole of society, patients and practitioners alike) collective understanding of this deeply tragic case and the world in which it takes place.

\section{THE CLINICAL CASE}

On the morning of 18 February 2011, following a referral from his GP, six-year-old Jack Adcock was admitted to the Children's Assessment Unit (CAU) at Leicester Royal Infirmary, suffering from a temperature of 37.7 centigrade, diarrhoea, vomiting and difficulty breathing. Jack, who had Down's Syndrome, had had heart surgery (atrioventricular septal defect surgery to repair a hole in the septum that divides the four chambers of the heart) in his first year of life but was doing well with a daily maintenance dose of Enalapril, a drug that helps to regulate blood pressure. Jack was seen at around 10.30am by the doctor overseeing the CAU, Dr Hadiza Bawa-Garba. Bawa-Garba was a trainee paediatrician, at the beginning of the sixth year of her postgraduate specialty training (what is known as ST6). This was her first day back in practice after 14 months on maternity leave. It was also her first day of work at Leicester Royal Infirmary. Despite this, Bawa-Garba had been given no Trust induction into 
the hospital and its systems. Due to gaps in the staffing rota, and the absence of the CAU Consultant on site, Bawa-Garba was overseeing the Children's Assessment Unit, the emergency department and the CAU ward. ${ }^{2}$

Bawa-Garba assessed Jack as being seriously unwell and put him on supplementary oxygen. Diagnosing him with severe gastroenteritis she also prescribed him a fluid bolus (a rapid intravenous infusion of fluids) and ordered blood tests and a chest $\mathrm{x}$-ray. These tests were undertaken during the morning, with the blood tests coming back very quickly showing the red-flag marker of a high lactate level in Jack's blood, an indication of very low oxygen levels in his blood. His chest $\mathrm{x}$-ray results were reported around $12.30 \mathrm{pm}$ and suggested a severe chest infection.

Bawa-Garba was responsible for various other complicated cases between $12 \mathrm{pm}$ and $3 \mathrm{pm}$ across the six areas of the hospital in which she was working, including performing a lumbar puncture (the procedure in which cerebrospinal fluid is collected from the spinal canal for diagnostic testing) on a baby. She was finally able to review Jack's x-ray at 3pm (of note, she had not been informed that this x-ray had been reported at 12.30pm), and immediately prescribed antibiotics to treat what she then correctly diagnosed as pneumonia. In the time since she had last seen him, Jack seemed to have picked up somewhat and was drinking from a beaker and playing with the radiographer. He continued to stay in the Unit under the care of an agency nurse, Isabel Amaro. Although Nurse Amaro's clinical experience was in adult care, she was covering CAU because the hospital was also suffering shortages in nursing staff. Staffing shortages were compounded by problems with IT facilities and failures in the hospital computer system meant that Jack's blood test results were not available until $4.15 \mathrm{pm}$ in the afternoon. At $4.30 \mathrm{pm}$, Bawa-Garba had a handover meeting with her consultant, Dr Stephen O'Riordan, a paediatric endocrinologist who had returned to the hospital from teaching at another site. She drew his attention to the blood test results and her diagnosis of Jack's pneumonia but she didn't specifically ask O'Riordan to review him. O'Riordan chose not to examine Jack himself, despite having ultimate responsibility for his care. Bawa-Garba spoke to O'Riordan again at $6.30 \mathrm{pm}$ but again he did not examine Jack. In her case notes, Bawa-Garba did not expressly instruct that Jack's daily dose of Enalapril should not be dispensed while he was so unwell. Enalapril has the effect of lowering blood pressure, and given his dehydration, pneumonia and signs of shock, it was profoundly contraindicated. Jack's mother administered his evening dose of the drug when he was transferred to the ward at around $7 \mathrm{pm}$ and at around $8 \mathrm{pm}$, Jack collapsed with cardiac arrest. Bawa-Garba responded to the crash call that went out from the ward. Along with the crash team, she started resuscitation on Jack but then, confusing him with another child, called off the attempts to revive him, mistakenly thinking he was under a DNR order ('Do Not Resuscitate'). Another trainee doctor on the team realised the mistake, identified Jack correctly, and resuscitation was restarted after a hiatus of between 30 seconds to 2 minutes. Despite the team's best efforts, they could not revive Jack and he died at $9.20 \mathrm{pm}$. In fact, though it was missed by both Bawa-Garba and O'Riordan, Jack's pneumonia had caused him to go into septic shock and, after post-mortem, cause of death was given as 'systemic sepsis complicating a streptococcal lower respiratory infection (pneumonia) combined with Down's syndrome and the repaired hole in the heart'. ${ }^{3}$

An event involving a death of this kind, in which serious medical errors play a part, is known as a Serious Untoward Incident (SUI) and it is necessary within NHS-funded services to launch an official investigation. ${ }^{4}$ In the immediate aftermath, six days after Jack's death, Bawa-Garba was called to a meeting with her consultant O'Riordan, which took place in the hospital canteen. O'Riordan asked her to complete a Training Encounter Form, in order to reflect upon the events of the case and the errors made. They completed this form jointly, with BawaGarba apparently reflecting that her errors involved failure to interpret venous blood gases and biochemistry results, as well as 'a lack of clear communication' (Cohen, 2017). She refused to sign the form, however, because she disagreed with some of its contents. ${ }^{5}$

\section{THE LEGAL AND PROFESSIONAL REPERCUSSIONS OF THE CASE}

This tragic case has triggered seismic convulsions in the medical profession, its regulatory body the GMC and the general public at large. It has become a case of protean complexity, in legal, educational, cultural and political terms. In the months after Jack's death, in early 2012, despite having been assured by the Crown Prosecution Service that she did not have a criminal case to answer, Bawa-Garba was arrested and detained for questioning for

\footnotetext{
${ }^{2}$ This workload meant 'looking after six wards, spanning four floors, undertaking paediatric input to surgical wards 10 and 11 , giving advice to midwives and taking GP calls'. See Lyvia Dabydeen et al. An Account by concerned UK Paediatric Consultants of the tragic events surrounding the GMC action against Dr Bawa-Garba. Available at: http://54000doctors.org/blogs/an-account-by-concerned-ukpaediatric-consultants-of-the-tragic-events-surrounding-the-gmc-action-against-dr-bawa-garba.html (Accessed 20 May 2018).

${ }^{3}$ GMC v Bawa-Garba, High Court of Justice - Queen’s Bench Division, 25 January 2018 [2018] EWHC 76 (Admin), para 9. Available at: https:/ /www.blackstonechambers.com/news/gmc-v-dr-bawa-garba/ (Accessed 11 May 2018).

4 See NHS England's 'Serious Incident Framework: supporting learning to prevent recurrence' (2015). Available at: https://www.england.nhs.uk/wp-content/uploads/2015/04/serious-incidnt-framwrk-upd.pdf

${ }^{5}$ See Cusack, 2018.
}

(C) 2018 by Author/s 
over seven hours, despite having only delivered her second child two weeks before. ${ }^{6}$ During 2012 , University Hospitals of Leicester NHS Trust, comprised of a 14-person team, conducted a lengthy investigation into the death and concluded in August 2012 that it was impossible to locate a 'single root cause' for the incident, identifying six areas of individual and systemic error that contributed to Jack's death (Wickware, 2018). In December 2014, over three years after Jack Adcock died, Bawa-Garba and the nurses involved in his care were charged with Gross Negligence Manslaughter (Dyer, 2014)..$^{7}$ On 4 November 2015, Bawa-Garba was convicted at Nottingham Crown Court. On 8 December 2015, she was found guilty of manslaughter, on a majority verdict of 10 to two, after 25 hours of deliberation by the jury. Six days later, on 14 December, she was given a two-year suspended sentence. ${ }^{8}$ After being denied the right to make an application to the Court of Appeal to have this criminal conviction quashed in December 2016, Bawa-Garba's future as a clinician had to be considered and decided by the Medical Practitioners Tribunal Service (MPTS). ${ }^{9}$ In June 2017, the MPTS ruled that she should be suspended from practice for a period of 12 months in order to demonstrate remediation (meaning, in this instance, providing evidence of learning and reflection about the particular medical errors she had committed). This decision went against the GMC's application to have Bawa-Garba struck off the medical register (known as 'erasure') permanently. In a highly unusual move, the GMC then took the MPTS to the High Court in December 2017, to argue that the Tribunal's sanction of suspension was insufficient. In a fervently reported and highly charged decision, the High Court upheld the GMC's appeal and overruled the MPTS' decision and on 25 January 2018, Bawa-Garba was struck off.

Since that decision, media coverage has intensified exponentially, with different groups pulling stridently in oppositional directions to support either Jack Adcock's parents, allied with notions of the public good or healthcare practitioners, and most specifically doctors, in increasingly binarised terms. On 28 March 2018, Bawa-Garba was granted the right to a second appeal against her erasure from the medical register. High profile professional campaigns to support Bawa-Garba gathered unprecedented momentum, a crowd-sourced fund to obtain an independent legal opinion on her case raised over $£ 350,000$ within days of being opened. Regulatory, political and legal responses proliferated, resulting in various strategic reviews into issues of discrimination in the regulation of the profession, the use of reflective practice in medical education and the Health and Social Care Secretary's ordering of a review into the current use of manslaughter laws in healthcare. ${ }^{10}$

\section{THE 'SPECTRE' OF 'PUBLIC CONFIDENCE'}

It is important to understand, as lay people, how extraordinary the GMC's appeal to the High Court is. In this action, the GMC, the chief regulator of the medical profession, called into question the professional decisions of its own Tribunal and also simultaneously marked this case out as a unique disciplinary example through which to

\footnotetext{
${ }^{6}$ As Lyvia Dabydeen et al. describe, Bawa-Garba's treatment during this questioning is cause for concern: 'She was detained by police for seven hours away from her baby who was fully breast fed, refusing bottles and at risk of hypoglycaemia. Bawa-Garba was in no state to face sustained police questioning and sign documents'. See Dabydeen et al. An Account By Concerned UK Paediatric Consultants Of The Tragic Events Surrounding The GMC Action Against Dr Bawa-Garba. Available at: http://54000doctors.org/blogs/an-account-byconcerned-uk-paediatric-consultants-of-the-tragic-events-surrounding-the-gmc-action-against-dr-bawa-garba.html (Accessed 20 August 2018).

${ }^{7}$ The legal definition of Gross Negligence Manslaughter, as defined by the Crown Prosecution Service, is: 'where the death is a result of a grossly negligent (though otherwise lawful) act or omission on the part of the defendant'. See https://www.cps.gov.uk/legalguidance/homicide-murder-and-manslaughter. There is widespread concern amongst the medical profession about the notable increase in manslaughter charges brought against doctors since the 1990s. This concern articulated through campaigning groups such as 'Manslaughter and Healthcare' (see http://www.manslaughterandhealthcare.org.uk), who are collating evidence to argue against the use of this culturallegal trend.

8 On 6 August 2016, nurse Isabel Amaro was removed from the nursing register by the Nursing and Midwifery Council and, unlike in BawaGarba's case, there has been no professional response mobilised in her defence. There is not space within the scope of this article to consider her conviction and erasure, but there is critical work to be done about the considerable impact of this case upon the regulation of nursing and nursing standards, as well as discussion about the differential status between doctors and nurses and its detrimental impact upon their cultural and regulatory treatment.

${ }^{9}$ In order to practice medicine in the UK, all doctors must be registered with the GMC. If eligible, and upon payment of fees, they are listed on the medical register and granted a licence number. This licence can be revoked in the event of a doctor's practice being found unprofessional. The Medical Practitioner Tribunal Service is the organisation that hears and decides upon sanctions in cases of complaint against doctors. It has a duty to report its decisions to the GMC.

${ }_{10}$ In February 2018, Jeremy Hunt ordered a rapid policy review into gross negligence manslaughter in healthcare, led by his senior clinical adviser Professor Sir Norman Williams. Simultaneously, the GMC commissioned Dame Clare Marx to undertake a review into how gross negligence manslaughter and culpable homicide (in Scotland) are applied to medical practice. The Williams Review published its recommendations in June 2018; one of the key outcomes has been the removal of the GMC's right to appeal the fitness to practise decisions made by the MPTS. Available at: https://assets.publishing.service.gov.uk/government/uploads/system/uploads/attachment_data/file/ 717946/Williams_Report.pdf. (Accessed 6 August 2018).

In April 2018, the GMC commissioned academics Roger Kline and Doyin Atewologun to lead a research project examining the prevalence of BAME doctors referred for 'fitness to practice' issues.
} 
reinforce 'public confidence' in the profession. The range and definitions of the sanctions applicable to doctors in the UK is laid out in the MPTS' document 'Sanctions guidance'. The section 'Maintaining public confidence in the profession' states that:

Patients must be able to trust doctors with their lives and health, so doctors must make sure that their conduct justifies their patients' trust in them and the public's trust in the profession (see Good Medical Practice, paragraph 65). Although the tribunal should make sure the sanction they impose is appropriate and proportionate, the reputation of the profession as a whole is more important than the interests of an individual doctor. ${ }^{11}$

This is the repeated claim made by the GMC in its push for Bawa-Garba's erasure. In his press statement made after the High Court decision, the Chief Executive Officer of the GMC, Charles Massey, stated that 'in today's ruling the court has confirmed that the Tribunal was simply wrong to conclude that public confidence in the profession could be maintained without removing the doctor from the medical register'. ${ }^{12}$ Massey here recycles the terms used by Mr Justice Ouseley in his Judgment on the case. Ouseley refers to issues of public confidence and invokes the jury's decision as a tangible expression of public opinion: 'I consider that the Tribunal did not give the weight required to the verdict of the jury, and was simply wrong to conclude that, in all the circumstances, public confidence in the profession and its professional standards could be maintained by any sanction short of erasure'. ${ }^{13}$ Yet his mobilisation of this notion of 'the public' is made more complex by the observation which immediately precedes his Judgment in which he notes that Bawa-Garba had continued to practice for almost seven years after Jack Adcock's death without a single further incident: 'Undoubtedly the fact that she has addressed the specific failings which arose suddenly and unexpectedly on that day, and that for many years afterwards she has practised safely and competently, is a factor which would weigh with "a fully informed and reasonable member of the public", a useful notion to invoke'. ${ }^{14}$ Ouseley's invocation of this figure of a 'fully informed and reasonable member of the public' is a compelling one to consider since the need to shore up the confidence of this figure drives the relentless endeavour to identify and sanction the member of the medical profession who has so grievously 'failed'. What might such a subject be and what discourses might create a 'fully informed member of the public? Barely six months after the Divisional Court decision to uphold the GMC appeal and erase Bawa-Garba's registration, the Court of Appeal met in late July 2018 to hear Bawa-Garba's Appeal against her erasure. Strikingly, the Appeal papers include the strong iteration by Bawa-Garba's Counsel of the 'wider public importance of the Appellant's appeal' and extensive discussion of notions of 'public confidence'. ${ }^{15}$ On August 13th 2018, in yet another twist to this complex case, the Court upheld Bawa-Garba's appeal and reinstated her to the medical register. In the recent aftermath of this crucial decision, there has been fervent discussion within the medical profession about change in working conditions within the NHS, the nature of medical regulation and the legal frameworks used in cases of medical error. A nationwide campaign titled 'Learn Not Blame' was launched during the Appeal case by Doctors Association UK which seeks to reconstruct the dominant model of blame within the NHS, and medical culture more broadly, into one which foregrounds the imperative of learning from mistakes, which it terms a 'just culture'. As Cicely Cunningham writes:

A just culture seeks to address the rawness of families' grief as well as the hurt of staff who are involved when tragedy strikes. A just culture seeks to learn from events and apply this learning to bring about change' (Cunningham, 2018).

I would argue strongly here that practice-based medical humanities has a role to play in this radical shift towards a just culture, since the compulsion towards blame in medical culture is buttressed by the same imperative around medical error within culture at large. One place to start in this regard is to excavate what was so destructively mobilised in this case around notions of 'the public' and 'public confidence'. To return to the GMC's now muchcriticised action of pursuing Bawa-Garba's erasure, when Charles Massey cites the protection and sustenance of

\footnotetext{
11 See Medical Practitioners Tribunal Service, 'Sanctions guidance', Para 16. Available at: https://www.mpts.uk.org/DC4198_Sanctions_Guidance_Dec_2015_64896602.pdf. Good Medical Practice is the core guidance document produced by the General Medical Council, which outlines the duty of a doctor and the definitions of professionalism in practice.

${ }^{12}$ Quoted in 'Full General Medical Council statement over decision to strike off Jack Adcock's doctor', Leicester Mercury, 25 January 2018. Available at: https://www.leicestermercury.co.uk/news/local-news/full-general-medical-council-statement-1116613 (Accessed 11 May 2018)

${ }^{13}$ GMC v Bawa-Garba, High Court of Justice - Queen’s Bench Division, 25 January 2018 [2018] EWHC 76 (Admin), para 53. Available at: https://www.blackstonechambers.com/news/gmc-v-dr-bawa-garba/ (Accessed 11 May 2018).

${ }^{14}$ GMC v Bawa-Garba, High Court of Justice - Queen’s Bench Division, 25 January 2018 [2018] EWHC 76 (Admin), para 52. Available at: https://www.blackstonechambers.com/news/gmc-v-dr-bawa-garba/ (Accessed 11 May 2018).

15 See Court of Appeal Civil Division, Appeal No.C1/2018/0356.
} 
'public confidence' as the reason for the GMC's drive for erasure, what evidence is he drawing on to determine how members of the public actually think and feel about this case?

\section{TENTACULAR THINKING IN THE BAWA-GARBA CASE}

What kinds of modes of knowledge can provide answers to these complex questions? Seemingly quantifiable notions of reasoning and understanding are here being applied to a notional 'ordinary' citizen in an apparently transparent way, yet the deployment of this putative figure, 'the member of the public', embeds a hidden agenda. Critical thinking here requires tools that allow analysis beneath the socio-cultural surface. Here, the critical tools offered by the feminist theorist of science and technology, Donna Haraway (2016), are productive. In her challenge to current descriptions of the epoch in which we are living as the Anthropocene, and its underpinning logic of humanity as the principal driver of existence on Earth, Haraway argues forcefully for a new epistemological paradigm which foregrounds our more modest status as beings interconnected to the earth and everything else that inhabits it. One of the structuring symbols for this new paradigm is a particular species of spider, Pimoa Cthulbu, specific to the redwood forests of North Central California near Haraway's home. The species name, Cthulhu, chosen by its identifier Gustavo Hormiga, references H.P. Lovecraft's short story 'The Call of the Cthulhu' (1928) in which an all-powerful underwater deity commands a human cult (Hormiga, 1994). ${ }^{16}$ The name provides Haraway with a symbol for systems of elemental natural power that vastly outweigh human capability. Moreover, the spider, in its web-making practices and limited geographical spread, reminds her that 'nobody lives everywhere; everybody lives somewhere. Nothing is connected to everything; everything is connected to something' (Haraway, 2016: 31). Building on the twin images of webs and underwater creatures, Haraway outlines a new epistemological model, tentacular thinking. The word 'tentacle', Haraway remembers, comes from 'the Latin tentaculum, meaning "feeler", and tentare, meaning "to feel" and "to try" (Haraway, 2016: 31). Thus, tentacular thinking recognises that all things are connected, though these connections are often subterranean and occluded, and socio-cultural power and control are embedded in these deep structures. 'Tentacularity', she argues, 'is about life lived along lines - and such a wealth of lines - not at points, not in spheres' (Haraway, 2016: 32). We cannot then proceed to deep understanding of the world, and our actions within in, without a model of thinking that acknowledges and explores the fundamental interconnectedness of things. For Haraway, the tentacular nature of existence also requires a radical revision of modes of action in the world. Alongside the multitudinous examples of collectivity offered by feminist activism, the insistent pressures of environmental concerns lead Haraway to argue for what she calls sympoiesis: 'Nothing makes itself', she notes, 'Nothing is really autopoietic or self-organizing' (Haraway, 2016: 58). Like Despret's concept of 'thinking-with', sympoiesis articulates the need for collaboration in human being and action, in the best and most productive sense. It also identifies the contrasting, reductive process of autopoiesis, the kind of omnipotent 'self-making' practices that dominate much of socio-cultural life by compartmentalising areas of human governance and experience. The organisations of medical regulation (as, perhaps, with many other such professional organisations), might be seen as understanding themselves as autopoietic, deracinated from the broader networks of culture in which they nevertheless sit, and autonomous in their enactment of regulation and alleged safeguarding of 'the public'.

Whilst these terms may feel, in their abstraction, at too radical a remove from the Bawa-Garba case, I suggest that they give us traction on its protean complexity. The notion of 'tentacularity', somewhat like Gilles Deleuze and Felix Guattari's philosophical use of the botanical rhizome, provides a way of conceptualising lines of power, deep and hidden associations, modes of production and seemingly unconnected repercussions in far-flung locations of cultural life (Deleuze and Guattari, 2004). Tentacular thought about the question of the 'public' to whom Massey apparently refers allows us to follow the lines of connection between the medical regulation in the form of the GMC, the government oversight and legislation of healthcare, the role of the law, and the systems of mass communication that intervene in the generation of public understanding. The most prominent organ of mass communication is, of course, the media, with its self-appointed role in mobilising public feeling about this and other cases, and in particular the British middle-market tabloids, such as the Daily Mail and its online version, the MailOnline. ${ }^{17}$ The Daily Mail began its reporting of the case in late July 2013 (Wilkes, 2013). In this early reporting, the headline focus is on Jack Adcock's identity as a 'Down's syndrome boy' and Bawa-Garba's mistake is attributed to exhausting working conditions. The Daily Mail picks up reporting again in December 2014, after Bawa-Garba and nurses Amaro and Theresa Taylor have been charged with manslaughter, following an investigation by Leicestershire police (Duell, 2014). Notably, the headline focus shifts to the clinical team, placing Bawa-Garba, as doctor, first and Jack's identity is recorded as 'boy, six with Down's syndrome'. This subtle but important

\footnotetext{
${ }^{16}$ For the short story see H. P. Lovecraft. (February 1928). The Call of the Cthulhu. Weird Tales.

${ }^{17}$ Since its public reach is so much larger than the print version of the newspaper, I focus specifically on the reporting of the case in the MailOnline.
} 
reorganisation of identity descriptors augurs the move in focus which will come to dominate in the reporting which picks up pace in early October 2015, in the run up to Bawa-Garba's court appearances to answer the charges of manslaughter (Mullin, 2015). For the first time, a photograph of Bawa-Garba appears in print, placed alongside a photograph of Jack Adcock. This reveal photograph of Bawa-Garba, taken as she arrives at Nottingham Crown Court, gives a visual representation of her ethnicity and presumed religious identity. From this point on, photographs of Bawa-Garba in al-Amira hijab dominate the extensive Daily Mail coverage. As Leila Ahmed has so powerfully argued, the hijab is legible through many, often contrasting, frames of reference (Ahmed, 2011). Despite the nuances of its use for Muslim women themselves, and as Ahmed notes, these are multiple and not reducible to simple narratives about religious observance, the hijab as cultural signifier in certain dominant Western contexts is freighted with deeply problematic, racist meaning (Ahmed, 2011: 13). My question in relation to these photographs is what lines of connection are being manipulated by the newspaper and consequently drawn by a biased white readership? On 6 November 2015, two days after Bawa-Garba is convicted of manslaughter, the paper runs an interview with Nicola Adcock, Jack's mother. In a paragraph placed next to a close-up face shot of Bawa-Garba, Daily Mail interviewer Jenny Johnston writes: 'When Jack stopped breathing, instead of pouring every effort into saving his life, she ordered staff to stop saving him. Dr Bawa-Garba, who is originally from Nigeria but qualified as a doctor in Britain, and who is a mother of two herself, had recently returned from maternity leave' (Johnson, 2015). The issue of Bawa-Garba's ethnicity is returned to later in the interview when Johnson writes: 'Dr Bawa-Garba moved to Britain from Nigeria in 1994 to be privately educated at an international school near Reading. She told the Court that her parents felt she would "do better in the UK" (Johnson, 2015). On the afternoon of 14 December 2015, immediately after the Court decision to hand down a two-year suspended sentence the Daily Mail prints two photographs of Bawa-Garba and Jack Adcock. ${ }^{18}$ Into the vortex of this already fraught case, the strategic placement of these photographs alongside each other and the print report of the suspended sentence, animates potent narratives about power, identity and vulnerability. These photographs are of faces, and faces, as Deleuze and Guattari argue, represent both individual and cultural identity, faces are 'engendered by an abstract machine of faciality (visagéité), which produces them at the same time as it gives the signifier its white wall and subjectivity its black hole' (Deleuze and Guattari, 2004: 187). From a feminist perspective, thinking-with about the case, the image of these paired faces sounds with deep, alarming resonance about gender, childhood, disability, ethnicity, religion. The 'political' work the faces do is to pitch these already disadvantaged and vulnerable subjectivities against each other, subliminally (or perhaps not so subliminally after all) asking the 'public' to reductively read one as powerful perpetrator, the other as powerless victim. ${ }^{19}$ Foregoing any nuanced understanding of the complex intersectionality of all identity (to follow Crenshaw and those who have theorised intersectionality in her wake ${ }^{20}$ ), which might note that in their shared marginalisation these 'opposites inhabit each other', this image rather instantiates a brutal binary of identity (Hekman, 1999: 5). Indeed, to deploy a humanities lens here, in psychoanalytic terms, and specifically those of Melanie Klein (Klein, 1930), this media representation incites the reader to 'split' these faces into 'good' and 'bad' objects. ${ }^{21}$ Klein details the ways in which the aggressive psychic defence of splitting is reactivated in adult life in states of anxiety. The primal affects stirred up by the tragedy of Jack Adcock's death, combined with more generalised fears of bad medical practice and the failure of medicine to save and cure, make for a potent mix of readerly feelings. Whilst the causal relationship between tabloid representation and the 'public' understanding of complex, emotive cases with deep human interest is a difficult one to untangle, it is clear that this kind of reporting both ventriloquises and shapes the perception and affects of the lay public. This particular article drew 72 comments from readers, the majority of which yoke ethnicity and poor medical practice, identifying it as 'common' knowledge that doctors from ethnic backgrounds are 'bad doctors'. ${ }^{22}$ Many of these comments call for the deportation of Bawa-Garba and her family, and articulate 'injustice' in the fact that Bawa-Garba's own disabled son is still alive, while Jack Adcock is not. The issue of BawaGarba's primary medical qualification and country of origin had been circulating in the public domain for some time but here coalesce as markers of 'incompetence'.

To what extent does the remarkable decision made by Charles Massey, to 'safeguard' public confidence by appealing and overturning the MPTS decision to suspend rather than erase Bawa-Garba, turn upon this kind of anxiety and prejudice aroused through media coverage within the public domain? And what happens to Mr Justice Ouseley's emblematic figure of the 'fully informed and reasonable member of the public' in these conditions? The journalist and broadcaster Nick Ross, involved in dimensions of clinical governance and professional regulations

\footnotetext{
18 For images see http://www.dailymail.co.uk/news/article-3359630/Doctor-nurse-guilty-manslaughter-six-year-old-s-syndrome-boyconfusing-DNR-patient-walk-free-court-given-suspended-sentences.html (Accessed 12 May 2018)

${ }^{19}$ I cannot fully explore the nature of the 'vulnerability' of Muslim women here but direct the reader to the work of Lila Abu-Lughod for a crucial exploration of its complexity, see Abu-Lughod, 2013.

${ }^{20}$ See Crenshaw, 1989.

${ }^{21}$ Klein's writings on infant development, object relations and the mechanisms of the paranoid-schizoid in which splitting behaviours dominate are manifold, however for a succinct account see Klein, 1930.

22 See Readers' comments (Cockcroft, 2015).
} 
in various ways including being the longest serving member of the Royal College of Physicians Ethics Committee and Non-executive director of Imperial NHS Healthcare, writes to Professor Terence Stephenson, Chair of the GMC, challenging the GMC's actions and calling into question the role of the media: 'as a journalist and broadcaster I suspect that one of the factors might have been pressure from the media, and I should remind you that newspaper reporters are out to make a story, not nuanced judgements, and whose printed morals tend to be the finger-wagging variety' (Ross, 2017: 359). He continues, 'I believe in this case [the GMC] overstepped its responsibilities. I worry it may have been influenced by vocal and angry coverage, added to which there are unfortunate and immeasurable risks that vengefulness, racism and xenophobia might have played a part' (Ross, 2017: 359). Stephenson's response to Ross, which, following Haraway, we might characterise as profoundly autopoeitic, details various points to do with legal and regulatory practice but studiously avoids picking up on the issue of racism and media influence in the GMC's actions. ${ }^{23}$

Another line of tentacular connection needs to be followed here. The regulator's avoidance of this discussion in his public correspondence with Nick Ross might nevertheless be contextualised by the multiple instances of bias embedded within the structures of medical culture. As various commentators have noted, these issues arise repeatedly in the institutional networks that govern and regulate medical training and practice, such as the Royal Colleges and the General Medical Council itself. These are perhaps symbolised best by the 2014 Judicial Review of the Royal College of General Practitioners (RCGP) licensing exams (the membership exams which confer the right to practise as a GP), which was requested by the British Association of Physicians of Indian Origin (BAPIO). BAPIO accused the College of failing to discharge its Public Sector Equality Duty (PSED), and with directly and indirectly discriminating against international medical graduates (IMGs). BAPIO's evidence for this discrimination was the stark differential attainment for IMG and BAME doctors in College exams, particularly the clinical skills assessment exam, in which candidates are examined undertaking clinical scenarios with a role player. ${ }^{24}$ The interconnectedness of lines of discrimination can be unearthed as systemic problems, as Amitava Banerjee notes:

As well as the difficult immigration climate for those coming to the UK, institutional racism is still a major problem in the NHS. [....] There is evidence of racism in selection, assessment, and training of doctors. In the 1990s, a national study and one focusing on London medical schools found that BME applicants were less likely to be selected than their white counterparts. In the past few years, there has been much controversy regarding potential racial biases in assessment of doctors, such as the MRCGP postgraduate exams. Historical data from the late 1980s suggested that BME doctors were six times less likely to obtain hospital jobs than their white counterparts with identical qualifications. The current situation has not been assessed. Lack of representation of BME staff in the upper echelons of the NHS has been recognised in a National Health Executive report, "The Snowy White Peaks of the NHS". Complaints are more likely to be against BME doctors, and when they proceed to the General Medical Council or the law courts, they are more likely to lead to more serious punitive measures and guilty verdicts. (Banerjee, 2018)

Here, we need to collectively endeavour to identify and address the strands of discrimination that weave through medical culture, as well as attending the potent and sometimes destructive affects that propel public reaction and appraisal of our healthcare systems. It is for practice-based medical humanities, modelled on feminist practice, to think-with medicine's institutions and organisations as they struggle with issues of equality, diversity and inclusion in their curricula, their modes of assessment and their regulation of the medical profession.

\section{THINKING-WITH IN THE WAKE OF BAWA-GARBA}

On 24 January 2018, four days before the High Court upheld the GMC appeal and struck Hadiza Bawa-Garba off the medical register, trainee anaesthetist Dr James Haddock started a Twitter campaign to support her with the hashtag \#iamhadiza. It started trending immediately and spread beyond Twitter to become an organising call to other medical professionals across the UK and indeed the world. The identificatory statement, modelled on the Twitter slogan 'Je suis Charlie' adopted by defenders of free speech in the wake of the Charlie Hebdo killings in Paris in 2015, immediately established an iterative community, capturing the deep sense of solidarity that many junior doctors felt with Bawa-Garba. A solidarity built on sharing the unsustainably pressured working conditions that had prevailed on the day of Jack Adcock's death, and the sense that by sheer luck their own medical errors had not resulted in such tragic consequences. Perhaps the most eloquent example of this solidarity is the front cover of the GP magazine Pulse, published on 1 March 2018 (Figure 1), in which 141 GPs gave their permission to have their photographs in a collage overlaying one of the images of Bawa-Garba that had been circulating in the media. This

\footnotetext{
23 See Stephenson, 2018.

${ }^{24}$ For a good overview of this case see Rendel et al., 2015.
}

$10 / 15$

(C) 2018 by Author/s 


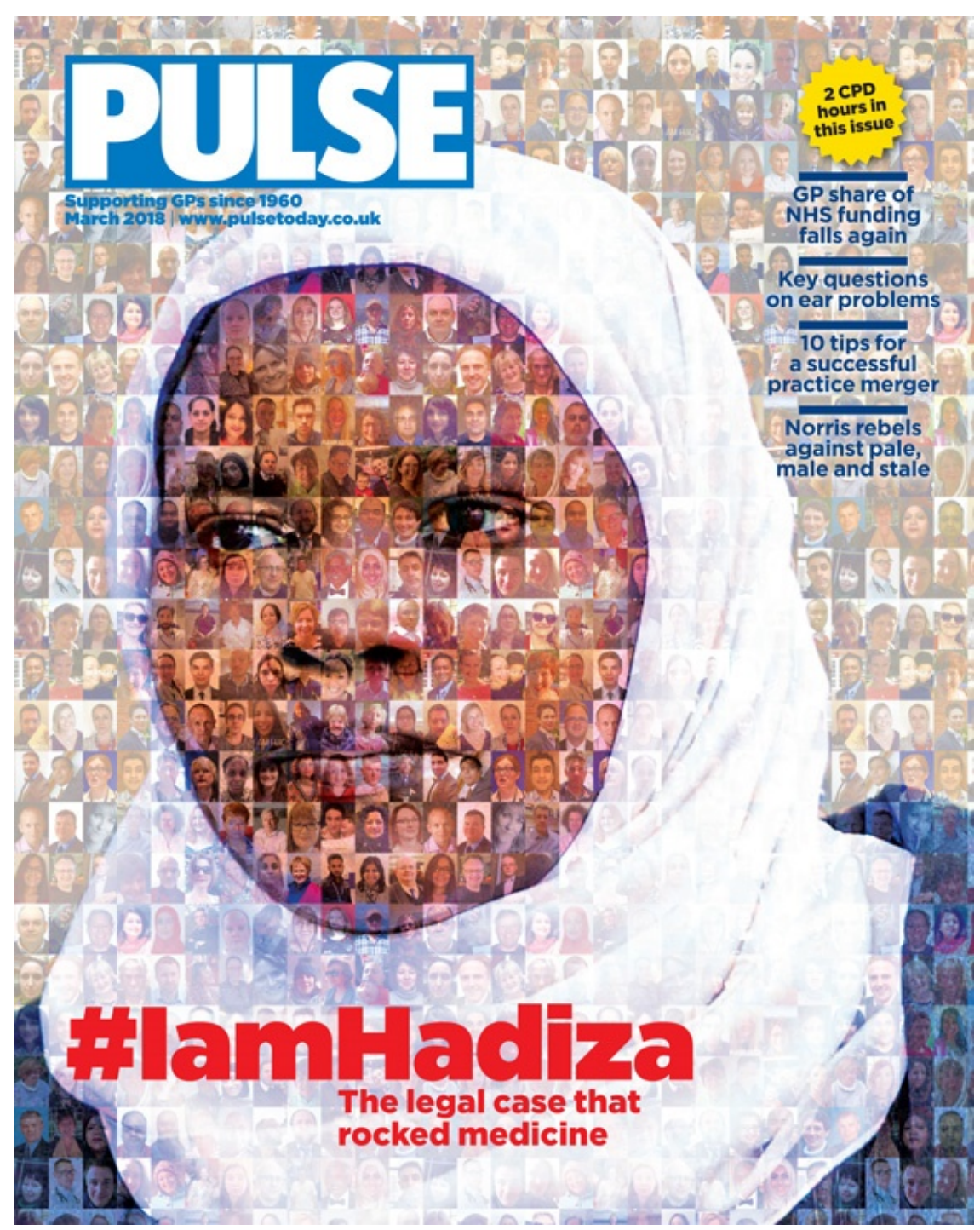

Figure 1. Pulse, 1 March 2018

symbolic statement of identification with her has the double effect of both multiplying ethnic identities and yet at the same time reducing them to a single identity, as all the participants acknowledge they could have stood in her shoes.

In addition to the assertive political statement about ethnicity, there is another key reason that these feelings of identification are so strong. One of the most incendiary details of the whole legal case, for other trainee doctors, is the reported exposure of Bawa-Garba's written reflections to the adversarial barrister of the prosecution. Multiple accounts recall with horror that her written reflections have ended up as material evidence in court, as documents that 'admit' her culpability (Kaffash and Gregory, 2018). The Health and Social Care Secretary Jeremy Hunt himself went on national radio the day after the verdict was delivered to state that: 'For patients to be safe, we need doctors to be able to reflect completely openly and freely about what they have done, to learn from mistakes, to spread best practice around the system, to talk openly with their colleagues. I want to make sure doctors are able to do that'. 25

It is important to understand the place of written reflection within medical culture. Within the system of British medical education, reflection has become an intrinsic educational tool, constituting a major component of the educational portfolio (e-portfolio) that trainees must submit to demonstrate learning and progression. Written reflection is used to help trainees develop 'the skills of self-reflection and self-appraisal that will be needed throughout a professional career'. ${ }^{26}$ In addition, written reflection is required of all doctors in their annual appraisals (Launer, 2015: 357). In cases of medical error or bad medical practice that have come to the MPTS for sanction, written reflection forms part of the evidence that a doctor has remediated and is fit to practice. The

\footnotetext{
25 'Jeremy Hunt says doctors must be allowed to discuss mistakes’, BBC News. Available at: http://www.bbc.co.uk/news/health-42833028 (Accessed 20 May 2018)

${ }^{26}$ The Gold Guide (7th Edition), January 2018, p. 48. Available at: https://www.copmed.org.uk/gold-guide-7th-edition/the-gold-guide-7thedition (Accessed 20 May 2018). The Gold Guide is the reference guide for postgraduate speciality training in the UK.
} 
Bawa-Garba case has, to quote John Launer, put 'reflective writing in medical education' under 'significant threat' (Launer, 2018: 314). Responses from the profession signify an entrenchment in relation to written reflection. GPs have imposed a boycott on reflective entries in their appraisal processes (Bostock, 2018). The Royal College of Physicians and Surgeons in Glasgow has issued guidance that urges caution amongst trainees undertaking reflective writing, stating: 'if you do choose to write a reflective report, ensure that it is fully anonymised. [....] Avoid emotive language, any suggestion of culpability or judgmental statements about any patient or staff who may be involved'. ${ }^{27}$ How might practice-based medical humanities think-with the medical profession as it struggles to work through these deeply problematic, anxiety-making attacks upon one of the cornerstones of its safety practice? Over and above making a strong defence for the need of reflective practice, via corollary examples from our own research practices, it is useful here to articulate a critical understanding of what writing is, and can do. John Launer outlines the benefits of writing to other doctors: 'The act of writing itself creates new and original ideas. By recalling an event, slowing it down in your mind, and anatomising it in writing, you can deepen your understanding of it, and even alter your perception of what happened' (Launer, 2015: 357). Yet the defensive retraction of what we might call key elements of writing's ability to do this in the RCPSG's advice above - identity, emotion and judgment would seem to strip the activity of its utility in reflective practice, removing its capacity to allow for affective processing and learning. Medical humanities might usefully critique what the court thought it saw in the artefact of Bawa-Garba's Training Encounter Form. Autobiographical writing, literary studies will explain, is located in both temporal and spatial terms; it occurs in a time and a place that changes with every iteration. Moreover, to record an event in narrative form is to present one version of events, but neither the workings of memory nor linguistic form are static or 'true' in any absolute sense. Over and above the contested nature of this particular instance of reflective writing (as I detail above, this form was only signed by Stephen O'Riordan, Bawa-Garba's consultant), it is strongly debatable, using humanities' tools, whether reflective writing should ever be included in the documentary materials of a legal case. If we return to feminist epistemology, there is a larger point to be made here about the role of reflective writing within medical education. Feminist researchers across the disciplines have long pushed for a shift towards reflexivity, rather than reflection, in feminist research practice. To quote feminist geographer Kim V. L. England, reflexivity is a 'self-critical sympathetic introspection' and 'a self-conscious analytical scrutiny of the self as researcher' (England, 1994: 244). Lorraine Nencel argues that 'reflexivity is both epistemological — how we should learn about knowledge, as well as methodological — how we should do research to obtain this knowledge' (Nencel, 2014: 76). Moreover, as Wanda Pillow argues, the practice of reflexivity prompts direct change in practice: 'Reflexivity under feminism is not only about investigating the power embedded in one's research but it is also about doing research differently' (Pillow, 2003: 178). There is both ethical and intellectual force in the ability to stand outside one's own interpretive actions and consider both oneself and the 'object' of research. We might understand it as a $360^{\circ}$ turn, which takes the researcher back to the self in order to explore how she herself is embedded within the processes of communication with and interpretation of her research subjects. This constitutes an altogether deeper level of self-reflection that the $180^{\circ}$ line between writing subject and her written reflection. To what extent might the model of this more complex practice, in which the doctor and her thoughts, feelings and actions become as much the objects of exploration as the patient, be a more productive model for educational purposes than the written reflections now so jeopardised by the Bawa-Garba case? Not least, in educational terms, there is more scope for actual learning and change. Moreover, feminist models of reflexivity go hand in hand with notions of praxis, which describes the putting of theory into action. As Liz Stanley argues: 'Feminism outside of the academic mode has insisted on the crucial need for useful knowledge, theory and research as practice, on committed understanding as a form of praxis ('understand the world and then change it')' (Stanley, 2013: 12). Praxis, rather than practice, requires transformation as a result of critical analysis, producing 'knowledge [...] not simply defined as "knowledge what' but also as "knowledge for" (Stanley, 2013: 15). This would seem to be a far closer approximation of the desired effect of self-reflection within clinical practice and education. Practice-based medical humanities, as it draws on feminist theory, might thus instructively promote reflexive praxis, rather than reflective practice, within medical education, remediation and appraisal.

Importantly, in conclusion, notions of reflexive praxis take us back in a $360^{\circ}$ turn to the place at which this article begins, considering the model of a practice-based medical humanities that is built upon feminist epistemological insights and lessons from feminist theory and action. To what extent does reflexive praxis currently appear in the methodologies presently deployed in the competing iterations of medical humanities as a set of disciplines? I would argue that the field, alongside the medical culture it purports to analyse, has yet to properly achieve these principles of practice, preferring the practice of thinking about to that of thinking-with. To return to the appeal made by Julia Kristeva and her collaborators, their call to the medical humanities to rethink its 'grounding assumptions' and to collaborate in the dismantling of the old but still prevailing and instrumentalised

\footnotetext{
27 Royal College of Physicians and Surgeons in Glasgow. (2018). The case of Hadiza Bawa-Garba v GMC. Available at: https://rcpsg.ac.uk/news/2480-the-case-of-hadiza-bawa-garba-v-gmc (Accessed 20 May 2018)
} 
binary opposition between "'the objectivity of science" and the "subjectivity of culture", this appeal surely requires an urgent response (Kristeva et al., 2017: 55). My contention is that it is feminist theory which will best provide the conceptual tools to help move beyond the reductive binary of medicine and the humanities that has prevailed, and that it is its epistemological paradigms which open out the necessary generative space for asking questions, for conversation, for joint problem-solving and collective action.

\section{REFERENCES}

Abu-Lughod, L. (2013). Do Muslim Women Need Saving? Cambridge, MA: Harvard University Press. https://doi.org/10.4159/9780674726338

Ahmed, L. (2011). A Quiet Revolution: The Veil's Resurgence, from the Middle East to America. New Haven: Yale University Press.

Banerjee, A. (2018). Institutional racism is still a major problem in the NHS. BMJ Opinion. Available at: http://blogs.bmj.com/bmj/2018/01/31/amitava-banerjee-institutional-racism-is-still-a-major-problem-inthe-nhs (Accessed 12 May 2018).

Barad, K. (2007). Meeting the Universe Halfway: Quantum Physics and the Entanglement of Matter and Meaning. Durham, NC: Duke University Press. https://doi.org/10.1215/9780822388128

Bates, V., Bleakley, A. and Goodman, S. (eds.) (2013). Medicine, Health and the Arts: Approaches to the Medical Humanities. London: Routledge. https:// doi.org/10.4324/9780203079614

Bleakley, A. (2015). Medical Humanities and Medical Education. London: Routledge.

Bostock, N. (2018). GPs boycott reflective entries for appraisal after Bawa-Garba case. GPOnline. Available at: https://gponline.com/gps-boycott-reflective-entries-appraisal-bawa-garba-case/article/1455704 (Accessed 20 May 2018)

Bourdieu, P. (1984). Distinction: A Social Critique of the Judgement of Taste. London: Routledge.

Chiavaroli, N. (2017). Knowing how we know: an epistemological rationale for the medical humanities. Medical Education, 51, 13-21. https://doi.org/10.1111/medu.13147

Cockcroft, S. (2015). 'What about my son? Mother's fury as doctor who let boy die goes free after pleading she has to care for her own disabled cbild'. Available at: http://www.dailymail.co.uk/news/article-3359630/Doctor-nurse-guiltymanslaughter-six-year-old-s-syndrome-boy-confusing-DNR-patient-walk-free-court-given-suspendedsentences.html (Accessed 12 May 2018).

Cohen, D. (2017). Back to blame: the Bawa-Garba case and the patient safety agenda. BMJ, 359. https://doi.org/10.1136/bmj.j5534

Crenshaw, K. (1989). Demarginalizing the intersection of race and sex: A Black feminist critique of antidiscrimination doctrine, feminist theory and antiracist politics. Feminist in the Law: Theory, Practice and Criticism. University of Chicago Legal Forum, 139-168.

Cunningham, C. (2018). The Court of Appeal was right to reinstate Dr Hadiza Bawa-Garba. The Guardian. Available at: https://www.theguardian.com/commentisfree/2018/aug/14/court-appeal-right-reinstate-dr-hadiza-bawagarba (Accessed 20 August 2018).

Cusack, J. M. (2018). How should doctors use e-portfolios in the wake of the Bawa-Garba case? BMJ, 360. Available at: https://www.bmj.com/content/360/bmj.k572/rr. (Accessed 11 May 2018) https://doi.org/10.1136/bmj.k572

Deleuze, G. and Guattari, F. (2004) A Thousand Plateaus: Capitalism and Schizophrenia. Trans. Brian Massumi. London: Continuum.

Downie, R. S. (2016). Medical Humanities: some uses and problems. Journal of the Royal College of Physicians of Edinburgh, 46(4), 288-294. https://doi.org/10.4997/JRCPE.2016.416

Duell, M. (2014). Doctor and two nurses charged with manslanghter after boy, six, with Down's syndrome died in hospital. Available at: http://www.dailymail.co.uk/news/article-2878568/Doctor-two-nurses-charged-manslaughterboy-six-s-Syndrome-died-hospital.html. (Accessed 12 May 2018).

Dyer, C. (2014). Doctor and two nurses charged with manslaughter over death of boy at Leicester Royal Infirmary. BMJ. (Accessed 11 May 2018) https:// doi.org/10.1136/bmj.g7755

England, K. V. L. (1994). Getting Personal: Reflexivity, Positionality, and Feminist Research. The Professional Geographer.
46(1),

England.pdf?sequence $=1$ \&isAllowed $=y \quad$ (Accessed 20 May 2018) https://doi.org/10.1111/j.00330124.1994.00080.x

Fitzgerald, D. and Callard, F. (2016) Entangling the Medical Humanities, in A. Whitehead et al. (eds.) The Edinburgh Companion to the Critical Medical Humanities (pp. 35-49). Edinburgh: Edinburgh University Press. 
Haraway, D. (2016). Staying with the Trouble: Making Kin with the Chthulucene. Durham, NC: Duke University Press. https://doi.org/10.1215/9780822373780

Hekman, S. (1999). Identity, Identity Politics and Beyond. Critical Review of International Social and Political Philosophy, 2(1), 3-26. https://doi.org/10.1080/13698239908403266

Hinchliffe, S. (2015). More than One World, More than One Health: Re-configuring Interspecies Health. Social Science and Medicine, 129, 28-35. https:/ / doi.org/10.1016/j.socscimed.2014.07.007

Hormiga, G. (1994). A Revision and Cladistic Analysis of the Spider Family Pimoidae (Araneoidea: Araneae). Smithsonian Contributions to Zoology, 549, 1-104. https://doi.org/10.5479/si.00810282.549

Johnston, J. (2015). "I thanked that doctor for trying to save my poor son. Now I know she killed him": As medic is convicted over manslaughter of "popular" six-year-old Down's Syndrome boy, his heartbroken mother reveals the gaping hole left in her life". Available at: http://www.dailymail.co.uk/news/article-3307700/I-thanked-doctor-trying-save-poor-sonknow-killed-medic-convicted-manslaughter-popular-six-year-old-s-Syndrome-boy-heartbroken-mothergaping-hole-left-life.html (Accessed 12 May 2018).

Kaffash, J. and Gregory, J. (2018). Revealed: how reflections were used in the Bawa-Garba case. Pulse. Available at: http://www.pulsetoday.co.uk/news/gp-topics/legal/revealed-how-reflections-were-used-in-the-bawagarba-case/20036090.article (Accessed 20 May 2018).

Klein, M. (1930). The Importance of Symbol Formation in the Development of the Ego. International Journal of Psycho-Analysis, 11, 24-39.

Kristeva, J., Moro, M. R., Ødemark, J. and Engebretsen, E. (2017). Cultural crossings of care: An appeal to the medical humanities. Medical Humanities, 55-58.

Latour, B. (2016). Foreword, in Vinciane Despret. What Would Animals Say If We Asked the Right Questions? Minneapolis: University of Minnesota Press.

Launer, J. (2015). What's the Point of Reflective Writing. Postgraduate Medical Journal, 91(1076), 357-358. Available at: http://pmj.bmj.com/content/91/1076/357 $\quad$ (Accessed $20 \quad$ May https://doi.org/10.1136/postgradmedj-2015-133514

Launer, J. (2018). Managing the threat to reflective writing. Postgraduate Medical Journal, 94(1111), 314-315. (Accessed 20 May 2018) https://doi.org/10.1136/postgradmedj-2015-133514

Mullin, G. (2015). Boy, 6, with Down's syndrome died "after hospital doctor called off life-saving treatment because she mistakenly thought he was under a Do Not Resuscitate order". Available at: http://www.dailymail.co.uk/news/article3262181/Boy-6-died-hospital-doctor-called-life-saving-treatment-mistakenly-thought-Not-Resuscitateorder.html (Accessed 12 May 2018).

Nencel, L. (2014). Situating reflexivity: Voices, positionalities and representations in feminist ethnographic texts. Women's Studies International Forum, 43, 75-83. https://doi.org/10.1016/j.wsif.2013.07.018

Pillow, W. (2003). Confession, catharsis, or cure? Rethinking the uses of reflexivity as methodological power in qualitative research. International Journal of Qualitative Studies in Education, 16(2), $175-196$. https:/ / doi.org/10.1080/0951839032000060635

Ross, N. (2017). Re: GMC to push for erasure of paediatrician convicted of manslaughter. BMJ, 359. (Accessed 20 August 2018) https:/ / doi.org/10.1136/bmj.j5223

Rendel, S., Foreman, P. and Freeman, A. (2015). Licensing exams and judicial review: the closing of one door and the opening of others? British Journal of General Practice, 65(630), 8-9. https:/ / doi.org/10.3399/bjgp15X683029

Stanley, L. (ed). (2013). Feminist praxis and the academic mode of production: an editorial introduction. Feminist Praxis: Research, Theory and Epistemology in Feminist Sociology. Abingdon: Routledge, 3-19. https://doi.org/10.4324/9780203094020

Stengers, I., Despret, V. and Collective. (2014). Women Who Make a Fuss: The Unfaithful Danghters of Virginia Woolf. Trans. April Knutson. Minneapolis: Univocal.

Stephenson, T. (2018). Response to Nick Ross letter of 8 February. BMJ, 360. (Accessed 20 August 2018) https://doi.org/10.1136/bmj.k481

Whitehead, Anne and Woods, Angela. (eds). (2016). Introduction, The Edinburgh Companion to the Critical Medical Humanities (pp. 1-31). Edinburgh: Edinburgh University Press.

Wickware, C. (2018). "No single root cause" found after Bawa-Garba SUI investigation. Pulse. Available at: http:/ / www.pulsetoday.co.uk/your-practice/regulation/no-single-root-cause-found-after-bawa-garba-suiinvestigation/20036369.article (Accessed 11 May 2018).

Wilkes, D. (2013). Down's syndrome boy, 6, died when doctor exhausted by 12-hour shift mistook bim for child who had 'do not resuscitate' order'. Available at: http://www.dailymail.co.uk/news/article-2375899/Jack-Adcock-6-died-doctormistook-child-resuscitate-order-him.html (Accessed 12 May 2018).

Woolf, V. (1993 [1938]). A Room of One's Own and Three Guineas. Harmondsworth: Penguin. 
Feminist Encounters: A Journal of Critical Studies in Culture and Politics, 2(2), 20

Citation: Winning, J. (2018). Learning to Think-with: Feminist Epistemology and the Practice-based Medical Humanities. Feminist Encounters: A Journal of Critical Studies in Culture and Politics, 2(2), 20. https://doi.org/10.20897/femenc/3888

Copyright (C) 2018 by Author/s and Licensed by Lectito BV, Netherlands. This is an open access article distributed under the Creative Commons Attribution License which permits unrestricted use, distribution, and reproduction in any medium, provided the original work is properly cited. 